\title{
Sophie Marchand, Théâtre et pathétique au XVIII siècle: pour une esthétique de l'effet dramatique
}

\section{Franco Piva}

\section{(2) OpenEdition}

\section{Journals}

\section{Edizione digitale}

URL: http://journals.openedition.org/studifrancesi/5940

DOI: 10.4000/studifrancesi.5940

ISSN: 2427-5856

\section{Editore}

Rosenberg \& Sellier

\section{Edizione cartacea}

Data di pubblicazione: 1 mai 2011

Paginazione: 166-167

ISSN: 0039-2944

\section{Notizia bibliografica digitale}

Franco Piva, «Sophie Marchand, Théâtre et pathétique au xvIII' siècle: pour une esthétique de l'effet dramatique», Studi Francesi [Online], 163 (LV | I) | 2011, online dal 30 novembre 2015, consultato il 12 janvier 2021. URL: http://journals.openedition.org/studifrancesi/5940 ; DOI: https://doi.org/10.4000/ studifrancesi.5940

Questo documento è stato generato automaticamente il 12 janvier 2021.

\section{(c) (i) () $\Theta$}

Studi Francesi è distribuita con Licenza Creative Commons Attribuzione - Non commerciale - Non opere derivate 4.0 Internazionale. 


\title{
Sophie Marchand, Théâtre et pathétique au XVIII ${ }^{\mathrm{e}}$ siècle: pour une esthétique de l'effet dramatique
}

\author{
Franco Piva
}

\section{NOTIZIA}

SOPHIE MARCHAND, Théâtre et pathétique au XVIII siècle: pour une esthétique de l'effet dramatique, Paris, Honoré Champion, 2009 («Les dix-huitièmes siècles», 124), pp. 841.

1 Il teatro settecentesco costituisce indubbiamente uno dei fenomeni più complessi e contraddittori dell'intera storia letteraria francese: condannato unanimemente per la sua scarsa originalità, visto come un'appendice assai poco interessante ed in qualche modo degenerativa del grande teatro classico, di cui avrebbe ripreso senza alcuna originalità temi e moduli, quello stesso teatro si caratterizza, tuttavia, per la sua straordinaria presenza all'interno della società francese del Settecento, di cui costituisce uno degli elementi indubbiamente incontournables, al punto che si è parlato spesso, e a ragione, di una vera e propria théâtromanie, ed è accompagnato da un dibattito teorico estremamente vivace, a segno dell'interesse che il teatro ha suscitato negli uomini più attenti del secolo dei Lumi, e dalla nascita di un certo numero di forme nuove ed innovative rispetto ad una tradizione alla quale gli uomini di teatro del Settecento guardano con un distacco cui la critica ha posto forse troppa poca attenzione. Come è possibile risolvere questa, almeno apparente, contraddizione, e dare finalmente al teatro, all'interno della letteratura settecentesca e della letteratura teatrale francese in generale, il ruolo e lo spazio che storicamente e criticamente gli spetta? È quanto ha cercato ed è riuscita brillantemente a fare Sophie Marchand con il corposo lavoro che qui presentiamo; un lavoro che riprende la thèse da lei discussa in Sorbonne qualche tempo fa e che si contraddistingue, occorre dirlo subito, per l'ampiezza dell'informazione su cui l'indagine si fonda, per il rigore con il quale il 
difficile discorso è stato portato avanti e per l'acutezza con la quale i vari problemi ad esso connessi sono stati affrontati.

2 Sophie Marchand è partita dalla constatazione più ovvia, in quanto da tutti ammessa: "le théâtre du XVIII siècle a été un théâtre pathétique», strettissimamente legato alla presenza quasi ossessiva delle lacrime («Les larmes sont partout, sur la scène tout autant que dans les salles de spectacle»); tuttavia, mentre agli occhi degli storici (che osserva maliziosamente l'autrice - quel teatro non hanno letto e quindi non conoscono se non per sentito dire) quella caratteristica («pathétique», «larmoyant», «touchant») è sinonimo di disvalore e, perciò, di condanna, e di condanna senza appello, per Sophie Marchand essa è il punto di partenza di un'indagine estremamente fouillée che pone il pathétique al centro di un mondo - quello del Settecento e del teatro settecentesco in specie - che proprio nel pathétique trova - a quanto pare-la sua espressione più autentica e completa; in quanto capace di dar conto della grande rivoluzione che il secolo conosce e che investe non solo il teatro ma l'intero modo attraverso il quale l'uomo del Settecento impara a conoscere se stesso ed il mondo che lo circonda; e di cui il teatro "pathétique» è, per l'appunto, uno degli aspetti più caratteristici e, per altro verso, quello nel quale questo nuovo modo di concepirsi e di strutturarsi trova la sua espressione più originale e pragmaticamente efficace.

Perché il teatro "pathétique» proprio di quella rivoluzione, antropologica oltre che ideologica e culturale, che caratterizzò il Settecento fin dai suoi inizi è -fa notare Sophie Marchand - figlio, e del grande dibattito che quella rivoluzione comportò sia a livello teorico che comportamentale. $\mathrm{E}$ il vivacissimo dibattito che fin dalla fine del Seicento e per tutto il secolo dei Lumi animò la vita teatrale francese, in particolare per quanto riguarda il ruolo che il teatro doveva svolgere all'interno della nuova società che da quel dibattito stava nascendo, e del modo migliore di raggiungere gli obiettivi che, all'interno di quella società, al teatro erano affidati, e che Sophie Marchand ricostruisce passo passo, ne è un significativo esempio. Un dibattito, per altro verso, che investe tutti i diversi aspetti che attengono al teatro: dalla costruzione della pièce, alla sua rappresentazione; dal suo rapporto con il pubblico al ruolo che in questo rapporto può, e deve svolgere l'attore, fino, per l'appunto, al ruolo che il teatro, quel teatro, deve svolgere all'interno della società da cui è nato. Un dibattito che non rimane solo astratto in quanto, accanto ai teorici, esso coinvolge coloro che quel teatro fanno, dagli autori delle pièces fino a coloro che a quelle pièces danno corpo, gli attori, ma anche gli scenografi ed i costumisti, per non parlare degli spettatori, che del teatro «pathétique» costituiscono uno degli elementi essenziali.

4 Il discorso svolto da Sophie Marchand è estremamente articolato e, come dicevamo, condotto con grande perizia e sagacia; per essere colto in tutta la sua stringente - $\mathrm{e}$ convincente-portata, esso avrebbe bisogno di essere seguito passo passo. Nell'impossibilità di farlo in questa sede, noi ci liniteremo a dire non soltanto che esso perviene a riabilitare storicamente, criticamente ma anche esteticamente quel teatro («pathétique») al quale, tradizionalmente, era stato riservato poco meno che un distaccato mépris, evidenziandone in modo efficace le ragioni d'essere e le finalità all'interno di un mondo assai più complesso, che coincide grosso modo con il mondo dei Philosophes, ma anche che la sua lettura aiuterà a farci del Settecento un'idea ed un'immagine più ricca, oltre che storicamente più esatta. Il Settecento che esce dalle pagine del grande lavoro di Sophie Marchand è infatti un Settecento più complesso e, nello stesso tempo, più convincente, e paradossalmente, più unitario, nel suo insieme, 
del pur interessante secolo che abbiamo da tempo imparato a conoscere e ad apprezzare, ma che gli ultimi studi - in particolare quelli sulle lacrime e sul pathos - ci hanno mostrato in dimensioni e secondo prospettive almeno in parte nuove, e foriere di ulteriori interessanti sviluppi. 